\title{
Reconceptualising Early Years Teacher Training: Policy, Professionalism and Integrity
}

\section{Dr Jo Traunter - The University of Hull}

\section{Submitted 19/07/2018}

\begin{abstract}
This paper seeks to identify the impact of the undergraduate Early Years Initial Teacher Training (EYITT) qualification on the emerging professional identity of a group of undergraduate students. The research explored the practical and academic self-concepts of the trainee practitioners together with wider societal perspectives gained through an examination of the associated policy context. The research data was transcribed and a process of sorting, coding and analysis was undertaken at several levels to form constructs, a thematic framework was then utilised to organise the data.. Findings indicate that, in failing to establish full parity between those who hold the title 'Early Years Teacher Status (EYTS)' and school teachers with 'Qualified Teacher Status (QTS)', the government has restricted the potential employability of EYTS, and their access to equality in pay and conditions, which causes confusion as to the status and role of the EYT. These factors, together with the absence of a related professional body, and a persistent government rhetoric which implies deficiencies in the quality of the ECEC workforce, have the potential to cause a dichotomy between the perceptions of professionalism in policy, theory and practice.
\end{abstract}

Key words: Professionalism, Identity, Workforce, Policy, Early Years Teacher, Training, Status

\section{Introduction}

The award of Early Years Teacher (EYT) and associated standards, was created following the Nutbrown report (2012). This report foreshadowed the creation of a new status, the 'Early Years Teacher Status' (EYTS), replacing its predecessor the 'Early Years Professional Status' (EYPS). The new route it was suggested, would focus on building more parity with teachers, as well as increasing professionalism within the sector. However, many within the profession questioned whether the lack of qualified teacher status (QTS) attached to the new qualification would ultimately impact positively on the professional recognition of practitioners (Nutbrown, 2012; Chalk, 2015). As such many issues remain unresolved, including the lack of pay and recognition 
for the role in the workplace, all of which impact on the professional identity of established and emerging early childhood professionals.

The rhetoric from government as articulated in the Early Years Workforce Strategy (2017) and its antecedent, More Great Childcare (2013), speaks of a clear commitment to raise the professional profile of early years practice within the sector. Yet there remains an incongruity between the commitment to develop the workforce (Mahadevan 2011), and the continued focus on the fact that they are somehow deficient and in need of transformation. Allen (2011) in his early intervention report commented;

'We must, therefore, ensure that all those working with children are adequately trained and I am aware that standards currently need to be raised'

(Allen 2011, 56)

Conversely research signifies that whilst the status of the workforce for early childhood may be low, there are strong indicators that practitioners working in the sector often create richer, more diverse and creative opportunities for young children's learning when compared to mainstream schooling (Hughes and Westgate, 2004; Davis and Barry, 2013).

Such messages in relation to the capabilities of the workforce perpetuate the continuing perception of low status and as Brock (2012) argues, instil a collective efficacy in practitioners. Collective efficacy being a term which describes a groups' shared perception of their own capabilities (Klassen and Usher, 2010). Such self-concepts are impacted upon by the attitudes of and interactions with others and within the society in which they function (Osgood, 2009). Indeed Brock (2012) argues that in relation to the ECEC community, 'although the skills and knowledge provide the tools for success within educational settings, it is the beliefs that the students (and others) hold about their capabilities to use these tools that ultimately counts' $(2012,43)$.

A contentious debate related to the provision for young children has thus emerged within the ECEC sector. This debate manifests in political and policy decisions which signify a way forward, and purports to offer the best care and learning opportunities for young children. The introduction of EYTS appears central in this debate, and is clearly positioned as a role which will contribute to the long term economic benefits of early childhood education (Gibson, 2013). 
Analysis of the discourse intimated in More Great Childcare (2013), suggested an introduction of policy priorities which consider the child as an economic unit. Evidence for such assertions were observed in references to parental employability and educational reformation. Such trends have also been observed by Woodrow (2011), who argues that economics is increasingly a catalyst for investment in ECEC, as opposed to the learning and wellbeing of young children. Woodrow (2011) warns that this indicates a worrying trend towards the marketization of early childhood. Yet justification for the marketization of ECEC argues that such policies promote a balance between supply and demand. Moss (2010) disputes these assertions, warning that parents in this model are encouraged to be consumers, demanding greater value for money and viewing ECEC as a commodity, one which demands a business model approach. Commentators such as Cleveland and Krashinki (2004), further warn against such approaches, arguing that ECEC should be viewed as a public good, and one which demands state support.

However the document 'More Great Childcare' (2013) carefully positioned the economic argument with justifications of reform for the greater good of society, promising to 'produce the brightest graduates and skilled school leavers; and reforming welfare so that it always pays to work' (DFE, 2013; 13). In this argument the government made the case for ECEC as enabling a more productive citizen, less reliant on state support and capable of a making a future contribution which allowed the nation to 'compete in the global race' (DFE, 2013; 6). These arguments present a model of a socially just education. Policy directions which indicate blatant inequality to those concerned, actively work against socially just ways of working, in this case ensuring the ECEC sector and those who train to work professionally within it are continually disadvantaged. Indeed the data which emerged from the participants in this study emphatically reinforced the sense of injustice they experienced and perceived both from government and the attitudes of society, which they believe are largely impacted by government policy and rhetoric.

\section{The rise of the early years professional}

There are multiple definitions of professional and notions of what constitutes professionalism in the ECEC sector are complex. Katz (1985) defined eight traits which indicated professional practice in the sector, social necessity; altruism; autonomy; code of ethics; distance from client; standards; training and specialist knowledge. Oberhuemer (2005) develped what she termed a democratic model of professional activity, identifying four features of professionalism, including interacting with children: care management and leadership; partnership with parents and 
knowledge base. Alternatively Brock (2012) encouraged practitioners to identify dimensions of their own professionalism, this resulted in the identification of seven traits including: qualifications, training and professional development; skills; autonomy; values; ethics and rewards. What is clear from the literature is that in common with the above studies, concepts of professionalism seem invariably linked to knowledge, knowledge production and knowledge application.

These notions contradict commentators such as Jónsdóttir and Coleman (2014) who argue that traditionally the role of the early years professional has often been viewed as that of the care giver, rather than that of an expert having specialist knowledge of ECEC. Therefore the concept of the graduate workforce within the profession has occurred later and faster than in comparable areas, with expectations changing for leaders within the sector to move from level 3 qualifications to level 6 in less than a decade (Osgood, 2006).

EYTS along with its predecessor the EYPS, are positioned in the intermediate position of being a recognised status nationally, yet having no related professional body or registration requirement. This thereby removes the higher level of scrutiny experienced by more established professions such as mainstream school teachers, medicine and social work, further indicating that working in the ECEC sector is very much an emerging profession (Osgood, 2009).

Historically therefore, early childhood practitioners in the UK have experienced an ongoing struggle to establish their professional status within the public domain. A re-conceptualisation of professionalism in the sector is now overdue, more importantly the voices of those working in the sector need to be heard to generate a more comprehensive perspective of professionalism for ECEC. Moyles (2001) argues that the sector requires a highly articulate workforce, with practitioners who are able to define what their own professionalism entails, in doing so she argues they become 'active agents of change' rather than passive recipients of policy' $(2001,90)$.

What is clear is that little investigation had been concluded into factors which impact on the professional identity of the new generation of early years teachers, together with the qualification and training route for EYTS. Therefore the intention of this research was to encourage students to question what it means to be a professional early years teacher, 
reflecting on personal meaning making and examining their own self beliefs and actions, together with that of others within the systems in which they operate.

\section{Methodology}

This paper reports on an investigation into how a group of students negotiated meaning and came to shared understandings of their professional identity. From this intersubjective perspective, quality of inquiry was based on whether all voices within the culture had been fairly represented. In doing so the data reflected a mutual understanding, demonstrating fairness and authenticity in the research process.

Evidence within this paper emerges largely from an online bulletin board focus group and a follow-up diamond ranking exercise. A sample of the nine first and second year female teacher trainees from the undergraduate BA Education and Early Childhood Studies programme with Early Years Teacher Status were invited to participate in the study. The students aged between twenty two and thirty three, were all of British origin and represented the full student cohort registered on the programme of study in one HE institution situated in the north of England. It is recognised herein that utilising a small sample may be limited in terms of the constituencies, characteristics and diversity it represents. However what this research does offer is a detailed exploration of the ways in which those becoming early years teachers make sense of this developing identity.

The bulletin board focus group method was selected to encourage students to reveal more of their own frame of reference. The analysis of the bulletin board focus group drew upon the work of Gibbs (2007) who suggests the importance of identifying the dominant discourses which shape students' subjectivities and ways in which they negotiate those subjectivities within the discourse.

Students participated in an asynchronous online discussion over the course of several days. During this time students signed in and out as convenient, not necessarily simultaneously. Questions were posed and responses invited, a short summary of the previous day's discussion was provided each day, this highlighted certain aspects of students' discussions before posting the next question. The bulletin board enabled a more reflective discussion, students had longer 
to consider their response providing more depth to the contributions they provided (Krueger and Casey, 2009).

The second method of data collection entailed a diamond ranking exercise (Rocket and Percival 2002), students were asked to define the characteristics of 'a high-status profession' by ordering nine statements which were drawn from the literature (Chalke, 2013; Dalli, 2008; Brock, 2012). In particular Brock's seven dimensions of professionalism were utilised; knowledge, education, skills, autonomy, values, ethics and reward, Brock (2006). Two additional statements were added in response to the data derived from the focus group responses, these related to professional accreditation and professional love. The statements used were:

- Those who have accreditation to practice, belong to a professional body eg QTS

- Those who meet a set of competence based standards successfully e.g. EYT standards

- Those who are awarded power and autonomy in the workplace, they lead others to develop practice

- Those who demonstrate an ethics of care, the ability to engage emotionally with the child and those around the child, e.g. families

- Practitioners who demonstrate professional love, those who are passionate about children and working with children

- Those who demonstrate a wide body of knowledge and the theory of ECEC acquired through formal training and study e.g. through graduate qualifications

- Ability to work and communicate as part of a multi professional team

- Reflective and reflexive practitioners, those that are capable of higher order thinking in and on practice

- Those who demonstrate the ability to create learning communities characterised by social justice and equality

Students working in groups of four and five were asked to rate their levels of agreement with each statement as to what traits were synonymous with a 'high-status profession'. Students ranked the statements in a diamond formation from most to least important. 


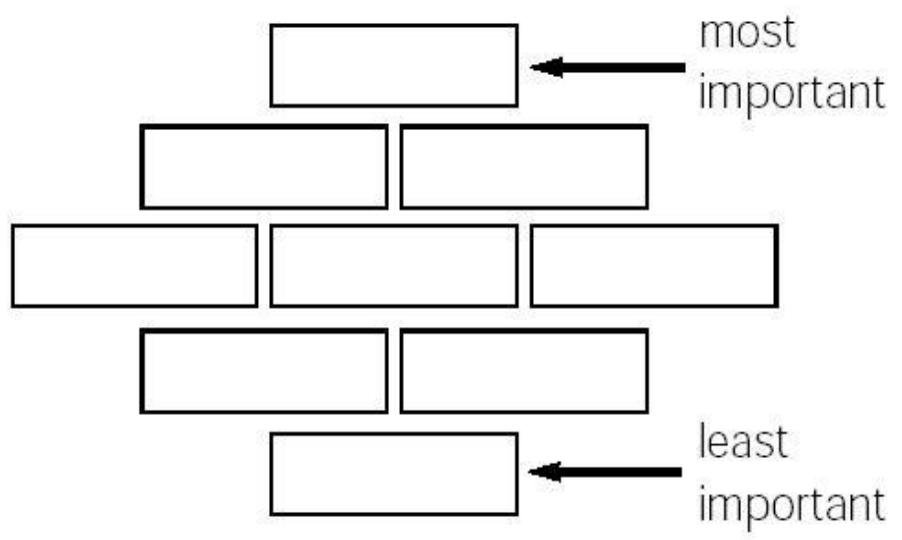

The strength of this method is in the idea that when participants rank statements, they are obliged to make explicit the principal relationships by which they organise their understanding, thereby making opinions available for analysis and comparison. The primary purpose of this exercise was not to measure the importance students placed upon each selected statement, but to facilitate discussion of the reasons students made particular choices or priorities.

The considerations drawn from the resultant data were then utilised to draw out relationships between examples and thus surface underlying constructs. The research sought to provide evidence of what students considered to be characteristics of professionalism in ECEC and reveal any tensions or unease in their understandings of who they are as professionals, their professed attitudes, values and beliefs and the impact of power relations on their aspirations and experiences of training on the EYT programme.

\section{Analysis}

The findings from the interrelated analysis of data across both methodologies revealed insights into students' perceptions of professionalism, values, experiences and aspirations. All data was transcribed and the sorting, coding and analysis was undertaken at several levels to form constructs. Once the coding had been conducted an initial thematic framework was constructed to organise the data. Three initial themes were identified, attitudes, aspirations and attributes, more detailed subthemes were then developed. These sub themes included relevance, value, personal perceptions, external perceptions, ambition and motivation. The indexing process was 
followed by the researcher sorting the material dependant on content to the thematic sets which were then organised into thematic matrices as identified above.

\section{Findings and Discussion}

\section{Early Years Teacher, Fact or Fiction?}

In defining their notions of professional practice in the sector, students turned their attention to the nature of the work and the types of skills they would need to define themselves as 'professionals'. The qualitative data revealed that students justified their motivation to choose EYT as a career pathway by reporting a strong desire to work with and for young children. This dedication to the work they do with children was often translated by participants to the word love. The recognition of love as a trait of professional practice is one recognised by writers such as Page (2011) and Dalli (2008), who countenance the practice of professional love as pedagogical tools. Others argue that it is precisely the notion of the soft maternal skills associated with love and caring which work to mitigate against the notion of work in ECEC as professional (Moyles, 2001; Maddon, 2012), warning that such cultures may be perceived as anti-intellectual.

Furthermore students' contributions in this study, recognised the skills needed in professional caring and felt that the knowledge and aptitudes necessary to deal with the complex and demanding work encountered by EYTs was not always acknowledged. The work of Noddings (1992) concurs with students' perspectives, identifying two types of care in teaching, virtue caring and relational caring. Noddings explains the complexity of professional practice as she describes the skills involved in being 'in relation' to someone before 'caring for' them. Noddings (1984) suggests that only by teachers having the skills to listen and respond to the child, encouraging them to play their part in the relationship, will the child become a dynamic agent in their own learning. Complementary to this, the notion of virtue caring focuses on planning for their learning and scaffolding behaviour. Responsibilities to care in these contexts demands professional competency and cannot be enacted without direct involvement with the children.

Additionally participants were keen to claim that being in possession of a wide body of knowledge was a trait for professional practice in the sector. Participants stated that in their experience the degree programme related to EYT did equip them with the skills and knowledge relevant to their future careers. Student narratives related to this aspect of professional identity 
were very confident in this conviction, as illustrated in the following extract from the online bulletin board focus group

"I feel that the EYT programme does prepare you for the work as an early years teacher. The tasks which we carry out contain elements seen in teacher practice. The range of placements allow you to see a variety of different practices carried out with different age groups and abilities enabling you to take on your own professional identity."

Osgood (2012) suggests that it is precisely these beliefs which allow practitioners to defend the profession and establish themselves as knowledgeable practitioners belonging to a developing community of practice. Students in this study demonstrated a strong argument related to the value of knowledge underpinned by theoretical principles. It is argued that one explanation for this may lay in the historical and cultural background to the profession, because professionals in the sector have traditionally struggled for recognition of the complexity of their work and parity in the terms and conditions they experience.

The evidence from this research, however, did not indicate that students saw little value in their practical training. On the contrary, one of highest ranking traits of professional practice identified by the students was the ability to think and act reflectively and reflexively and these skills, as they stated, were effectively developed through the practical training. Findings by Anning and Edwards (2010) concur, suggesting that reflective dialogue encourages opportunities to share understandings about practice (Anning and Edwards, 2010), allowing students to critically engage with discourses which underpin the development of professional identity (Osgood, 2006).

Yet participants, whilst supportive of the programme at university and were confident of the skills and knowledge they were developing, were reportedly aware of the limitations of the programme in relation to their chosen careers. A strong narrative, which emerged from the groups, discussed a lack of parity with their Qualified Teacher Status (QTS) counterparts training to teach in the primary, secondary or Further Education sectors. Students expressed concerns that their qualification, though equally as challenging and rigorous as other initial teacher training routes, lacked the respect and status offered to qualifications holding the title 'qualified'. These thoughts are reflected in the extract below

"Many assume that EYTS is inferior to QTS. It seems bizarre that something that takes the same length of training and rigour can be of less quality just because of the age 
range chosen, however pay scales and society's attitude towards EYTS and QTS would suggest that this is the case".

Furthermore the data suggested a perceived lack of parity in relation to participants' opportunities to practice and related remuneration within the maintained sector. This, the students argued, impacted significantly upon the professional identity of the workforce. These findings concur with those of Oberhuemer (2008), who argues that such perceived inequalities are inseparably linked to values and assumptions associated with cultural constructions of what constitutes professional practice. Therefore the value of EYT programmes as a route to professionalising the workforce for ECEC, it could be argued, has contributed little to the recognition of the professional character of the work. Participants expressed frustration that the importance of their role, and complexity of the work in which they are engaged, is not reflected in the terms and conditions they would expect for a professional role and one which is considered as equal in status to other members of the education profession. These sentiments and concerns are echoed by Skattebol, Adamson and Woodrow (2015), who argue that professional transformation within the workforce will never be recognised whilst the workforce continues to experience disaffection and marginalisation.

Responses to the inequalities experienced and articulated by the participants suggested that the strategy they had identified to overcome these factors was to enrol on a post graduate teacher training route (offering QTS) at the end of their studies. The students in their responses justified their actions in relation to widening the age group they would be entitled to teach and there was a discernible reluctance to link these choices to remuneration. The almost complete absence of references to financial rewards, could be explained by arguments presented by Gibson (2013). Gibson suggested that early childhood professionals may consider the image of the child as an economic unit, and childcare as business as unthinkable and in some ways distasteful. This, she argues, arises because the historical perception of work in the sector, is that of one being predominantly philanthropic and run by dedicated but largely low paid individuals. These values and traditions may explain the reluctance of participants to discuss economic considerations in relation to their chosen career. Whilst participants were eager to discuss the value their role could bring to the sector, and in particular their impact on children's lives, the expectation that they should be rewarded for this work in ways other than respect, status and opportunity to practice, was almost entirely absent from their narratives. 


\section{EYT, Professionalising or de-professionalising the workforce?}

It is clear from the data collected from both the online bulletin board focus group and the ranking exercise, that acknowledgement of the role, status and respect, were factors which impacted significantly on the emerging professional identity of students. Many of the participants have progressed to the programme from diploma level study and, as such, have some practical experience in the sector. Students in the study reported an intrinsic desire to work with young children in a professional capacity as a motivating factor to enrol on the programme of study. However a source of frustration expressed by the students related to references which demonstrated a lack of recognition or understanding about the status, with many students experiencing comments which suggested that a degree level qualification may be an unnecessary achievement for such work. These encounters are illustrated in the following extract from a conversation during the ranking exercise.

"...when I tell people what course I am doing and what age range I will be working with once I complete my degree, the reactions that I have very commonly received is 'oh so it is a bit like a babysitting course looking after young children and babies".

Such challenges to the value of the qualification may be particularly significant to the students, who reported negative past experiences related to the respect afforded to work in the sector. These encounters it is argued, contribute to the low self-esteem and disillusionment evidenced in some contributions, with participants discussing the need to be degree qualified and hold a professional status in order to command the autonomy and respect they felt marked professional practice. The impact of these past experience may be explained by referring to what Bourdieu (1985) terms 'habitus', which describes how status and identity may originate from a student's experiences. Bourdieu suggested that the juxtaposition of past and present histories, both personal and social, interrelate to develop professional identity. The newly introduced early years teacher status, having been introduced in response to demands for a higher qualified workforce, could be argued to have created challenges for the new recruits in overcoming previous academic habitus. Such challenges to the validity of the graduate status may engender uncertainty in relation to the legitimacy of their academic capabilities, what Bourdieu (1996) terms their academic legitimacy. 
Therefore the challenge for these emerging professionals in developing their professional identity appears to lay in the recognition of their newly introduced status and their opportunity to identify with a community of practice. The students in their discussions suggested that a continued lack of recognition for the status was additionally impacting on the support they accessed during their training. Participants stated that they struggled to distinguish which community they should align with, with settings lacking suitable role models to support training and mentor practice, as illustrated by the following contribution from the online focus group:

"I feel as though staff in the nursery where I do my placement don't understand that I am training to be an early years teacher. Some of them think I am a college student training to be a nursery nurse".

Additionally the rhetoric from government suggests that the early years teacher is affiliated with the teaching profession, with a set of EYTS standards aligned with those of teaching. However the profession enjoys none of the privileges or opportunity to practice, remuneration or status. The participants in this study indicated that their experience is that of a re-professionalisation agenda for the early years workforce, which closely reflects an approach associated with the current government agenda, one which Beck (2008) terms governmental professionalism. However, the students in this study expressed doubt over the relationship between the standards and professional practice, dismissing the standards as one of the lowest indicators of professional practice. These findings correlate to empirical research by Poet, Rudd and Smith (2010), which suggested that teachers in their study considered standards as a tool for professional development, yet in their daily work were of little relevance, being little more than a reference point.

Students' contributions concurred with these findings, stating that standards were tools to measure performance during training, yet did little to nurture a sense of professional identity for trainees. These perceptions are echoed in research by Evans (2011), who suggests that standards encourage little more than a performative agenda which encourages a technicist rather than a professional approach to practice. Urban (2005) concurs, warning against students measuring their professional identity by a paradigm of pre-determined and evidence-based outcomes, suggesting that in doing so they would be bound to failure. As the literature indicates, models of professionalism focused on performance management through targets and measures, appear to 
do little to foster the autonomous attitudes to practice, which are synonymous with professional behaviours (Ritchie, 2014). As Wood et al (2015) point out

'Aligning professionalisation with professional development has thus become an instrumental process with changes in practice only considered worthwhile if they result in improved learning outcomes for children'.

(Wood et al. 2015)

This paper therefore argues that EYT students in this study placed little importance on the standards by which they are judged because they struggle with the specific discourse related to outcome and performance standards, which they consider as inappropriate to the field of ECEC. Additionally, it is argued that the students regard the standards to have little significance in the development of their own professional identity, as they represent only a limited section of the work they undertake in the sector. This may arise because the standards are aligned with those of teaching, marking a discernible policy direction to focus on evidencing school-based competencies in early years provision. Therefore these standards reflect the work of only a narrow section of the workforce (Chalke, 2015) without truly reflecting the variety and context of work across the sector, and measuring set practice rather than evaluating professional competencies relevant to working with the youngest children.

Students further expressed concerns in relation to the nature of work that EYTS would ultimately prepare them for, and the roles they may occupy. One such concern is illustrated by the following extract where a participant states:

"I am aware of the different roles people with higher qualifications take within a setting, often people with higher qualifications are given roles within the office, more paperwork based rather than interacting with the children".

Whilst government rhetoric (NCTL, 2013), speaks of an ambition toward pedagogical leadership, students' narratives describe the graduate practitioner as one who is too often removed from practice. In order for ambitions of pedagogical leadership to materialise, it seems that the perception of leadership in the sector must also change (Murray and Macdonald, 2013). Participants in the study felt that concepts of leadership situated within a discourse of power did not sit comfortably with them, reflecting little of the central values of the transformational teacher who leads by example, one which they saw as relevant to leadership in the sector. 


\section{The context and impact of policy in the sector}

Participants in the study seemed reluctant to make direct reference to the wider impact of government policy and initiatives which impact on their developing professional identity. However, comments related to policy agendas and government discourses which did impact on their experiences, were implicitly referenced in many contributions in both the focus group and ranking exercise. These comments often referred to society at large, rather than pointing explicitly to specific government policy. These findings concur with those of Osgood (2010), who reported that the respondents in her study did not value discourses such as rationalism and accountability in discussions relating to their own emerging professional identities.

However, this paper argues that any consideration of factors which impact on professional identity must also look to the impact of macro systems. In the circumstances of this research, it was useful to interrogate the language and policy direction indicated in the document 'More Great Childcare' (2013). This document was, however, superseded at the close of this study by the 'Early Years Workforce Strategy' (DFE, 2017), which indicated that a consultation process would be imminent to revisit the entitlements offered to those who hold the title and status of EYT. However, as the data collection and analysis occurred within the period of time in which the policy direction for the children's workforce was governed by the More Great Childcare Document (2013), it seems pertinent that this document is the reference point for this paper.

The aforementioned professionalisation of the workforce into a teacher-modelled profession, articulated in the 'More Great Childcare' document (2013), appeared to cause significant confusion in relation to participants' professional identity. Students stated that the language used in initial documentation was misleading, claiming that decisions to enrol on the programme were impacted by the title 'teacher'. The title initially suggested to students that EYT provided a professional pathway which offered an equivalent status, enjoying equivalent benefits and opportunities, which participants later found to be inaccurate. Nutbrown (2013) agrees, arguing that the title of 'qualified teacher' is one which is widely understood in society, and therefore affords the holder status and respect. By denying the trainees on the early years teacher programme the opportunity to achieve a status which carries the word 'qualified' in the title, students are instantly disadvantaged in relation to how the qualification is understood or respected. Confusion caused by a lack of clarity in the title of the qualification is not new and 
corresponds to findings by Payler and Locke (2013) which identified similar tensions with EYT's predecessor the EYPS. The data in this paper points to the participants view that there is an apparent lack of commitment from the government in relation to awarding equality of opportunity to EYTs as to their QTS counterparts. In addition this lack of equality actively obstructs understanding of the qualification in the sector and disrupts students' emerging professional identity and confidence in the sector.

Furthermore, the participants in this study indicated that they believed that many practitioners in the sector do have the qualities and competencies of a professional workforce. However persistent references to inadequacies in the workforce observed in government policy literature, continue to point to inadequacies within the workforce, citing a lack of basic skills and a range of qualifications which 'lack rigour and depth' (DFE, 2013; 6). Participants felt that such rhetoric constantly derided the workforce and the respect it commanded, this they suggested could arise from a continual pursuit of evidence which indicated improvement in quality and outcomes, instigated by each successive government. Participants further contend that the messages which emerge in government rhetoric and policy direction, is reflected in the attitudes of the public whom they serve. Participants believed that without a clear articulation of the value of the qualification in the public domain, early years teachers would continue to struggle for the respect and autonomy for which they strive.

Analysis of the discourse within the 'More Great Childcare' (2013) document, articulated the language of quality in ECEC, firmly aligning the notion of quality alongside a perception of work in the sector which reflects a teacher-led model. Yet the document made little mention of the place of care in the profession. There appeared to be a clear policy direction emerging, one which whilst legitimising the demand for a graduate-led industry, was less concerned with care, and rather one which fixes firmly on academic learning and education. Woods et al (2015) argue that by equating the professional status of EYT with the training and standards appropriate to initial teacher training, government is defining the competencies, skills and knowledge that they consider appropriate to practice. Woods et al (2015) use the term 'governmentality' to explain this trend, arguing that such policy agendas impose considerably on professional values related to identities in the ECEC sector.

\section{Conclusions}


This research has aimed to establish early years teachers' perceptions of their own developing professional identity, together with the impact of the identified training route for EYTS. This paper suggests that findings indicate that constructions of professional identity in the sector are multifaceted and there is no simple solution to professionalising the workforce. What has become evident in the course of this investigation, is the importance of engaging students and trainers in the debate related to professional identity, as part of the complex journey to professional transformation of the workforce. In doing so, students have been encouraged to think expansively about the future of the profession, their hopes and aims for the sector and to consider the part that they could play in that future. Although the data were gathered at a particular point in time, the findings remain relevant in relation to the new Early Years Workforce Strategy (DFE, 2017) for England.

As a method of analysis, Integral Analysis (Wilber 2008) could be utilised as a methodology to examine further research agendas related to professional identity of the workforce, and related issues that have been identified as needing further research. Research agendas related to the professional identity of practicing graduates in the workforce, and that of non-graduate early years educators and communities of practice, could provide useful insights to the phenomena of professionalising the workforce for ECEC.

\section{Word Count 5825}

\section{References}

Allen, G. 2011. Early Intervention: The Next Steps. An Independent Report to Her Majesty's Government. London: HM Government.

Anning, A., and A. Edwards. 2010. Promoting Children's Learning from Birth to Five. London: Open University Press.

Beck, J. 2008. "Governmental Professionalism: Re-professionalising or De-professionalising Teachers in England?" British Journal of Educational Studies 56 (2): 119-143.

Bourdieu, P. 1985. "The Social Space and the Genesis of Groups." Theory and Society 14: 723-744. 
Bourdieu, P. 1996. "The Work of Time." In The Gift. An Interdisciplinary Perspective, edited by A. Komter, 136-148. Amsterdam: University Press.

Brock, A. 2012. "Building a Model of Early Years Professionalism from Practitioners' Perspectives." Journal of Early Childhood Research 11 (1): 27-44.

Chalke, J. 2013. "Will the Early Years Professional Please Stand Up, Professionalism in the Early Childhood Workforce in England." Contemporary Issues in Early Childhood 14 (3): 212-222.

Chalke, J. 2015. "Negotiating and Developing Professionalism: Early Years Practitioners' Stories of Professional Identity." EdD thesis. University of Sheffield.

Cleveland, G., and M. Krashinki. 2004. Financing ECEC Services in OECD Countries. Paris: OECD.

Dalli, C. 2008. "Pedagogy, Knowledge and Collaboration: Towards a Ground up Perspective on Professionalism." European Early Childhood Education Research Journal 16 (2): 171-185.

Davis, G., and A. Barry. 2013. "Positive Outcomes for Children: Early Years Professionals Effecting Change." Early Child Development and Care 183 (1): 37-48.

DFE (Department for Education). 2013. More Great Childcare, Raising Quality and Giving Parents More Choice. Accessed July 16,

2015. www.education.gov.uk/publications/standard/publicationDetail/page1/DFE-00002-2013.

DFE (Department for Education). 2017. Early Years Workforce Strategy. Accessed July 16, 2017. https://assets.publishing.service.gov.uk/government/uploads/system/uploads/attachment da ta/file/596884/Workforce strategy 02-03-2017.pdf.

Evans, L. J. 2011. “The 'Shape' of Teacher Professionalism in England: Professional Standards, Performance Management, Professional Development, and the Changes Proposed in the 2010 White Paper." British Educational Research Journal 37 (5): 851-870.

Gibbs, G. 2007. Analysing, Qualitative Data. London: Sage.

Gibson, M. 2013. "I Want to Educate School - Age Children': Producing Early Childhood Teacher Professional Identities." Contemporary Issues in Early Childhood 14 (2): 127-137. Accessed July 15, 2016. http://www.wwwords.co.uk/rss/abstract.asp?j=ciec\&aid=5447.

Hughes, M., and D. Westgate. 2004. "Teachers and Other Adults as Talk Partners for Pupils in Nursery and Reception Classes." In Cultural Worlds of Early Childhood, edited by M. Woodhead, D. Faulkner, and K. Littleton. London: Routledge.

Jónsdóttir, A., and C. Coleman. 2014. "Professional Role and Identity of Icelandic Preschool Teachers: Effects of Stakeholders' Views." Early Years: An International Research Journal 34 (3): 210-225. doi: 10.1080/09575146.2014.919574

Katz, L. 1985. The Nature of Professionalisms: Where is Early Childhood Education? Accessed September 8, 2014.

Klassen, R. M., and E. L. Usher. 2010. "Self-Efficacy in Educational Settings: Recent Research and Emerging Directions." Advances in Motivation and Achievement: Decade Ahead 16: 1-33. 
Maddon, R. 2012. "For Love or Money Exploring the professional identity of the Early Childhood Care and Education sector in Ireland Today." Published Thesis from Mary Immaculate College, University of Limerick.

Krueger, R. A., and M. A. Casey. 2009. A Practical Guide for Applied Research. London: Sage.

Mahadevan, J. 2011. "EYFS Has Improved Childcare in England, Ofsted Finds. Children and Young People Now." http://www.cypnow.co.uk/news/1054139/EYFSimprovedchildcare-England-Ofstedfinds.

Moss, P. 2010. "We Cannot Continue as We Are: The Educator in an Education For Survival." Contemporary Issues in Early Childhood 11 (1): 8-19.

Moyles, J. 2001. "Passion, Paradox and Professionalism in Early Years Education." Early Years: An International Research Journal 21 (2): 81-95.

Murray, J., and R. Macdonald. 2013. "Reframing Leadership as a Participative Pedagogy: The Working Theories of Early Years Professionals." Early Years 33 (3): 289-301.

NCTL (National College for Teaching and Leadership). 2013. Teachers Standards Early Years. Accessed April 6, 2014. https://www.gov.uk/government/publications.

Noddings, N. 1984. Caring, a Feminine Approach to Ethics \& Moral Education. Berkeley: University of California Press.

Noddings, N. 1992. The Challenge to Care in Schools: An Alternative Approach to Education. New York, NY: Teachers College Press.

Nutbrown, C. 2012. Foundations for Quality: The Independent Review of Early Education and Childcare Qualifications. Final Report. Runcan: Department of Education. www.education.gov.uk/nutbrownreview.

Nutbrown, C. 2013. Shaking the Foundations of Quality? Why Childcare Policy Must Not Lead to Poor Quality Early Education and Care. Sheffield: University of Sheffield.

Oberhuemer, P. 2005. "Conceptualising the Early Childhood Pedagogue: Policy Approaches and Issues of Professionalism." European Early Childhood Education Research Journal 13 (1): 5-16.

Osgood, J. 2006. "Professionalism and Performativity: The Feminist Challenge Facing Early Years Practitioners." Early Years: An International Research Journal 26 (2): 187-119.

Osgood, J. 2009. "Childcare Workforce Reform in England and the 'Early Years Professional', A Critical Discourse Analysis." Journal of Education Policy 24 (6): 733-751.

Osgood, J. 2010. "Reconstructing Professionalism in ECEC: The Case for the 'Critically Reflective Emotional Practitioner'." Early Years: An International Journal of Research and Development 30 (2): 119-133.

Osgood, J. 2012. Narratives from the Nursery. Negotiating Professional Identities in Early Childhood. London: Routledge. 
Page, J. 2011. "Do Mothers Want Professional Carers to Love Their Babies?" Journal of Early Childhood Research 9 (3): 310-323.

Payler, J., and R. Locke. 2013. "Disrupting Communities of Practice? How 'Reluctant' Practitioners View Early Years Workforce Reform in England." European Early Childhood Education 21 (1): 125137. doi: 10.1080/1350293X.2012.760340

Poet, H., P. Rudd, and J. Kelly. 2010. Survey of Teachers 2010: Support to Improve Teaching Practice. London: General Teaching Council for England.

Ritchie, J., J. Lewis, C. McNaughton Nicholls, and R. Ormston. 2014. Qualitative Research Practice, A Guide for Social Science Students and Researchers. 2nd ed. London: Sage.

Rockett, M., and S. Percival. 2002. Thinking for Learning. Stafford: Network Educational Press.

Skattebol, J., E. Adamson, and C. Woodrow. 2016. "Revisioning Professionalism from the Periphery." Early Years 36 (2): 116-131.

Urban, M. 2005. "Dealing with Uncertainty." Paper presented at the European Early Childhood Education Research Association. Accessed September 7,

2014. http://roar.uel.ac.uk/1744/1/2008 Urban Dealing-with-uncertainty.pdf.

Wood, E., J. Basford, J. Traunter, J. Payler, and J. Georgeson. 2015. De-professionalising or Reprofessionalising the Early Childhood Workforce in England. Accessed March 8, 2016. https://www.bera.ac.uk/blog/de-professionalising-or-re-professionalising-the-earlychildhood-workforce-in-england.

Woodrow, C. 2008. "Discourses of Professional Identity in Early Childhood: Movements in Australia." European Early Childhood Education Research Journal 16 (2): 269-280. 